WSRC-TR-93-139

\title{
ACID-PERMANGANATE OXIDATION OF POTASSIUM TETRAPHENYLBORON (U)
}

by J.R. Smith

WSRC-TR--93-139

Westinghouse Savannah River Company

DE93 011702

Savannah River Site

Aiken, South Carolina 29808

Other Authors:

This paper was prepared in connection with work done under Contract No. DE-AC09-89SR18035 with the U. S. Department of Energy. By acceptance of this paper, the publisher and/or recipient acknowledges the U. S. Government's right to retain a nonexclusive, royalty-free license in and to any copyright covering this paper, along with the right to reproduce and to authorize others to reproduce all or part of the copyrighted paper. 
WSRC-TR-93-139

Acid-Permanganate Oxidation of Potassium Tetraphenylboron (U)

J.R. Smith TS

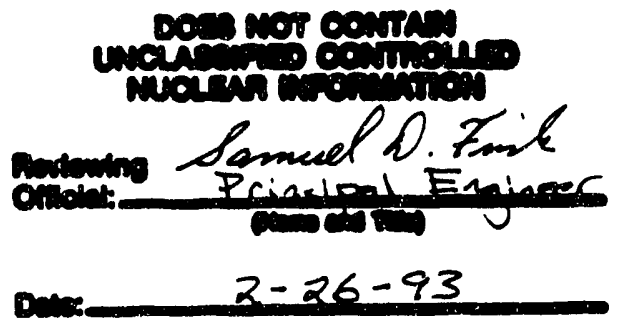

Westinghouse Savannah River Company

Savannah River Site

Aiken, SC 29808 


\section{DISCLAIMER}

This report was prepared as an account of work sponsored by an agency of the United States Government. Neither the United States Government nor any agency thereof, nor any of their employees, makes any warranty, express or implied, or assumes any legal liability or responsibility for the accuracy, completeness, or usefulness of any information, apparatus, product, or process disclosed, or represents that its use would not infringe privately owned rights. Reference herein to any specific commercial product, process, or service by trade name, trademark, manufacturer, or otherwise does not necessarily constitute or imply its endorsement, recommendation, or favoring by the United States Government or any agency thereof. The views and opinions of authors expressed herein do not necessarily state or reflect those of the United States Government or any agency thereof.

This report has been reproduced directly from the best available copy.

Available to DOE and DOE contractors from the Office of Scientific and Technical Information, P.O. Box 62, Oak Ridge, TN 37831; prices available from (615) 576-8401, FTS 626-8401.

Available to the public from the National Technical Information Service, U.S. Department of Commerce, 5285 Port Royal Rd., Springfield, VA 22161. 
WSRC-TR-93-139

$\mathrm{Pg} 1$ of 13

Acid-Permanganate Oxidation of Potassium Tetraphenylboron (U)

J.R. Smith

February 1993

Westinghouse Savannah River Company

Savannah River Site

Aiken, SC 29808 
WSRC-TR-93-139

$\mathrm{Pg} 2$ of 13

\section{CONTENTS}

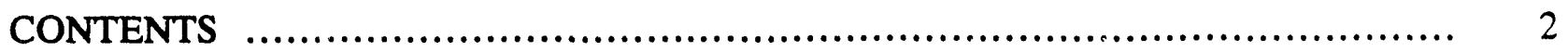

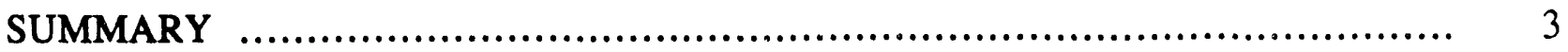

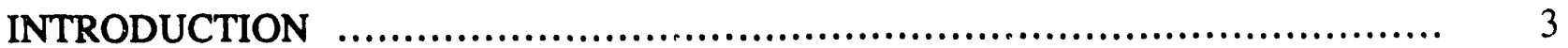

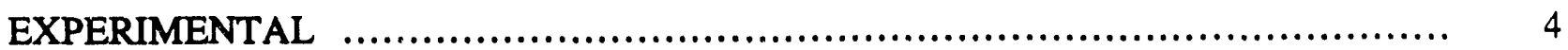

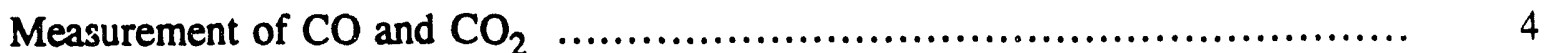

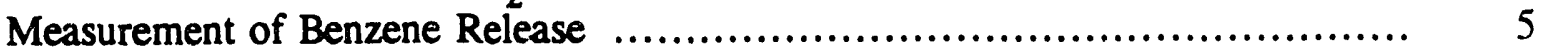

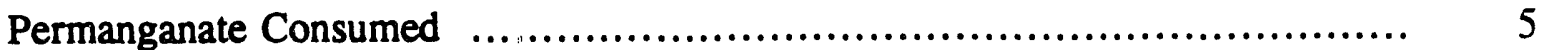

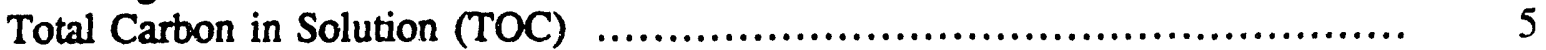

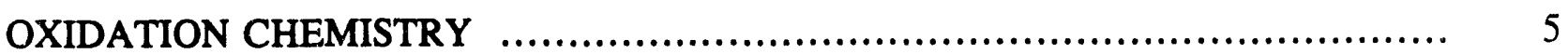

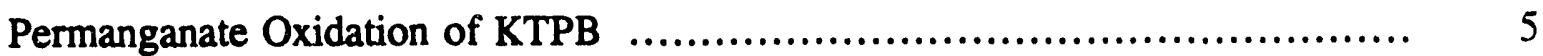

Decomposition of Acidic Permanganate Solutions ............................. 7

Oxalic Acid Reduction of Permanganate ..................................... 7

DISCUSSION ............................................................................... 7

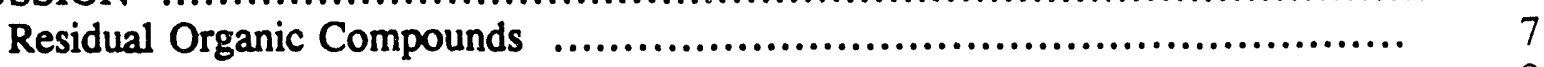

Benzene Vapor Loss ........................................................... 8

Residual Benzene In Solution ............................................... 8

Treatment of Solid KTPB …................................................... 8

Treatment of Dissolved TPB and Benzene ...................................... 8

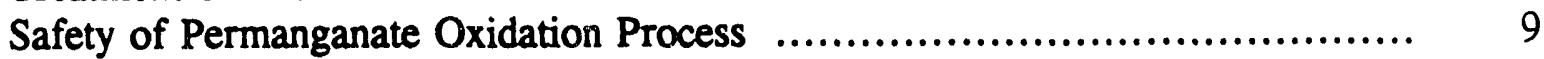

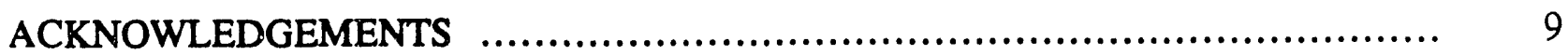

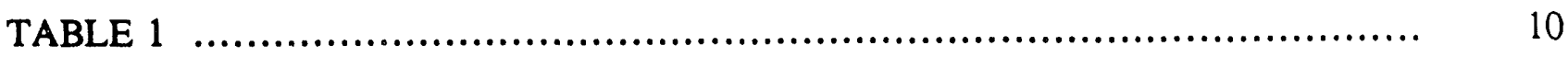

FIGURE 1 ......................................................................... 11

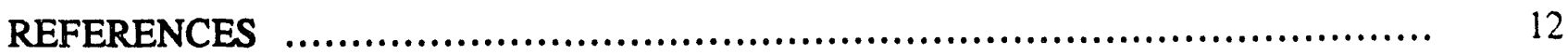


WSRC-TR-93-139

$\mathrm{Pg} 3$ of 13

\title{
Acid-Permanganate Oxidation of Potassium Tetraphenylboron (U)
}

\author{
by J. R. Smith \\ Westinghouse Savannah River Company \\ Savannah River Site \\ Aiken, SC 29808
}

\section{SUMMARY}

Scoping experiments have been performed which show that potassium tetraphenylboron (KTPB) is rapidly oxidized by permanganate in acidic solutions at room temperature. The main products are $\mathrm{CO}_{2}$, highly oxidized organic compounds related to tartaric and tartronic acids, boric acid, and potassium phosphate (when phosphoric acid is used as the source of acid). Jne liter of $0.6 \mathrm{M} \mathrm{NaMnO}_{4} / 2.5 \mathrm{M} \mathrm{H}_{3} \mathrm{PO}_{4}$ solution will destroy up to 8 grams of KTPB. The residual benzene concentration has been measured to be less than the RCRA limit of $0.5 \mathrm{ppm}$. Approximately $30 \%$ of the organic material is released as $\mathrm{CO}_{2}$ (trace $\mathrm{CO}$ ) and $0.16 \%$ as benzene vapor. The reaction is well behaved, no foaming or spattering. Tests were performed from $.15 \mathrm{M}$ to near $1 \mathrm{M}$ permanganate. The phosphoric acid concentration was maintained at a concentration at least three times that of the permanganate since an excess of acid was desired and this is the ratio that these two reagents are consumed in the oxidation.

\section{INTRODUCTION}

Analytical Development Section (ADS) support of the Waste Farm ITP process will produce residues containing alkali tetraphenylboron (TPB) and trace benzene in solution. These compounds and other RCRA listed hazardous materials must be removed before these waste solutions can be discarded to the SRTC High Level Waste Tanks. Other methods have been developed to remove hazardous metals such as lead, silver, mercury, and cadmium but a chemical process to remove benzene and its precursors, such as TPB, needs to be developed. Such a chemical process would need to destroy the TPB, benzene, and related compounds without the release of a large fraction of the TPB, as benzene, into the chemical exhaust ventilation system. Since the hydrolysis of TPB to benzene and boric acid is very slow at room temperature a process was sought that could accomplish the destruction of the phenyl groups of TPB at room temperature, before any benzene could even be produced. Other characteristic requirements of such a process are relative quickness, well behaved (no spattering or foaming), reaction in a single "accumulation" vessel (wouldn't need a permit), and ease of transformation to a state for further processing. 
WSRC-TR-93-139

$\mathrm{Pg} 4$ of 13

One chemical process that could possibly fit the above criteria was permanganate oxidation in acidic media. Permanganate is well known to rapidly oxidize carbon-carbon double bonds at room temperature. The reaction rate can be controlled by using a weak self-buffering acid such as $2.5 \mathrm{M}$ phosphoric acid and relatively dilute permanganate. Reaction conditions were sought which would sufficiently complete the oxidation in a few minutes to allow further processing. The excess permanganate can easily and quickly be destroyed with oxalic acid solution at room temperature.

This study has been performed to define the range of permanganate and phosphoric acid concentrations where TPB can be destroyed to benzene levels below the RCRA limit, $.5 \mathrm{ppm}$, at room temperature. This study was devised to determine the percentages of $\mathrm{CO}_{2}, \mathrm{CO}$, and benzene released as gas during the oxidation, thus allowing a carbon balance and a general characterization of the organic compounds left in solution.

\section{EXPERIMENTAL}

The original research plan was to use analysis support from Analytical Development Section (ADS) for trace benzene analysis and support from Intermediate Waste Technology (IWT) for offgas characterization, using a gas chromatograph (GC). 'The loss of GC support early in the research program necessitated the development of an on-line quantitative gas analysis process for $\mathrm{CO}_{2}$ and $\mathrm{CO}$. A method of checking this system was also developed using sodium oxalate and concentrated sulfuric acid to produce a quantitative amount of $\mathrm{CO}$ and $\mathrm{CO}_{2}(50$ mole\% each). The quantitative measurement of $\mathrm{CO}_{2}$ was performed using a weighed amount of ascarite, $\mathrm{NaOH}$ on a solid support. A flow-diagram of the reaction-analysis system is shown in Figure 1. The peristaltic pump was set to deliver $50 \mathrm{ml} / \mathrm{min}$. of air through the system. The air was first dried and scrubbed of $\mathrm{CO}_{2}$, with ascarite, just prior to entering the peristaltic pump. The air then swept the reaction vessel system of gaseous products. A measured amount of deuterated benzene was added to the system immediately after addition of the potassium tetraphenylboron (KTPB) sample to calibrate the dry-ice trap, used to measure benzene loss as vapor. Drierite, anhydrous calcium sulfate, is used to remove the last traces of water before the $\mathrm{CO}_{2}$ produced in the oxidation encers the first ascarite container. The ascarite bottle could be disconnected and weighed prior and during the actual oxidation reaction (the pump was turned off and the system sealed while the bottle was weighed). The system was checked for stability with repeated weighings prior to addition of KTPB. Any CO offgas would then be oxidized to $\mathrm{CO}_{2}$ by the oxygen in the air on the $\mathrm{Pd} / \mathrm{Kieselguhr}$ catalyst, maintained at $140^{\circ} \mathrm{C}$. This newly produced $\mathrm{CO}_{2}$ was then absorbed on another preweighed bottle of ascarite. The air sparge flowrate was measured using an inverted burette.

\section{Measurement of $\mathrm{CO}$ and $\mathrm{CO}_{2}$}

A quantitative amount of $\mathrm{CO}$ and $\mathrm{CO}_{2}$ can be produced by the dehydration of oxalate in concentrated sulfuric acid.

$$
\mathrm{C}_{2} \mathrm{O}_{4}^{2-}+2 \mathrm{H}^{+} \stackrel{\mathrm{H}_{2} \mathrm{SO}_{4}}{\longrightarrow} \mathrm{H}_{2} \mathrm{O}+\mathrm{CO}+\mathrm{CO}_{2}
$$


Heating to near $120^{\circ} \mathrm{C}$ for two hours is needed for quantitative generation. Even when the reaction is not complete the mole production of $\mathrm{CO}$ and $\mathrm{CO}_{2}$ is equal. The measured weights of $\mathrm{CO}$ (as $\mathrm{CO}_{2}$ ) and $\mathrm{CO}_{2}$ were always found to be nearly the same, $\pm 2 \%$, verifying that the $\mathrm{Pd} /$ Kieselguhr catalyst and both traps were working correctly. The reaction was considered complete when the weights of the ascarite traps became relatively constant for two hours. The measured values for $\mathrm{CO}$ and $\mathrm{CO}_{2}$ had an accuracy of about $\pm 2 \%$.

\section{Measurement of Benzene Release}

The dry-ice trap was used to measure the quantity of released benzene vapor. The trap was standardized by adding a measured amount of deuterated benzene $\left(\mathrm{C}_{6} \mathrm{D}_{6}\right)$ through the septum, between the reaction vessel and dry-ice trap, just after addition of the KTPB to the oxidizing solution. The assumption is that the trap will be equally as efficient for absorbing the deuterated benzene as for any benzene released from the oxidation. When the reaction was complete, approximately $6 \mathrm{ml}$ of absolute ethanol was added to the trap to dissolve the trapped benzene and deuterated benzene. The ethanol was then sent to ADS for trace benzene analysis. The ratio of the measured benzene to measured deuterated benzene times the amount of deuterated benzene added gave the total amount of benzene released in the oxidation. This value was compared to the maximum benzene possible from the KTPB added to get a percentage released.

\section{Permanganate Consumed}

The permanganate concentration in the oxidizing solution both prior and after the oxidation was measured using the McBride procedure ${ }^{1}$. This procedure uses the permanganate solution to titrate a $1.5 \mathrm{M}$ sulisuric acid solution containing a weighed amount of sodium oxalate. A persistent purple coloration marks the end-point of the titration. The permanganate concentration can easily be measured to an precision of $\pm .002 \mathrm{M}$ by this method and triplicate titrations.

Total Carbon In Solution (TOC)

Samples of the oxidizing solution were sent to ADS for TOC analysis. The values given by this method represent the quantity of organic material that can be oxidized completely to $\mathrm{CO}_{2}$, which is the species actually measured, in persulfate at elevated temperature. Not all organic compounds will be fully oxidized by this process. Any carbon not accounted for as TOC, benzene vapor, $\mathrm{CO}_{2}$, or $\mathrm{CO}$ is assumed to be in solution as highly oxidized, stable, organic material. •

\section{OXIDATION CHEMISTRY}

\section{Permanganate Oxidation of KTPB}

The oxidation of benzene, or TPB, by permanganate uses three moles of acid for every mole of permanganate. 


$$
6 \mathrm{MnO}_{4}^{-}+18 \mathrm{H}^{+}+\mathrm{C}_{6} \mathrm{H}_{6} \longrightarrow 6 \mathrm{Mn}^{2+}+12 \mathrm{H}_{2} \mathrm{O}+6 \mathrm{CO}_{2}
$$

In phosphoric acid the permanganate is completely reduced to $\mathrm{Mn}^{2+}$ (in base $\mathrm{MnO}_{2}$ is the final product). The oxidation of each carbon-carbon double bond of berizene requires the transfer of two electrons. Since manganese can't assume the +5 oxidation state, reaction with benzene is second order ${ }^{2}$. This requires that two molecules of permanganate approach each carbon-carbon bond simultaneously for oxidation. Planer organic compounds such as benzene accommodate oxidation by allowing approach from two sides, which is probably why this reaction is so rapid at room temperature. Other organic compounds which can attain a planer configuration, such as oxalic acid, also react rapidly. Permanganate in acid solution oxidizes all primary carbon atoms to carboxylic acids and nonprimary carbon atoms to first alcohols and more slowly to ketones ${ }^{3,4}$.

Permanganate attack on the phenyl (benzene) groups of TPE starts by oxidation of the three carbon-carbon double bonds to alcohols. Breakage of one of the carbon-carbon bonds in the resulting ring and oxidation of the primary, end, carbon atoms to carboxylic acid groups, which should be rapid ${ }^{3,4}$, results in mucic acid.

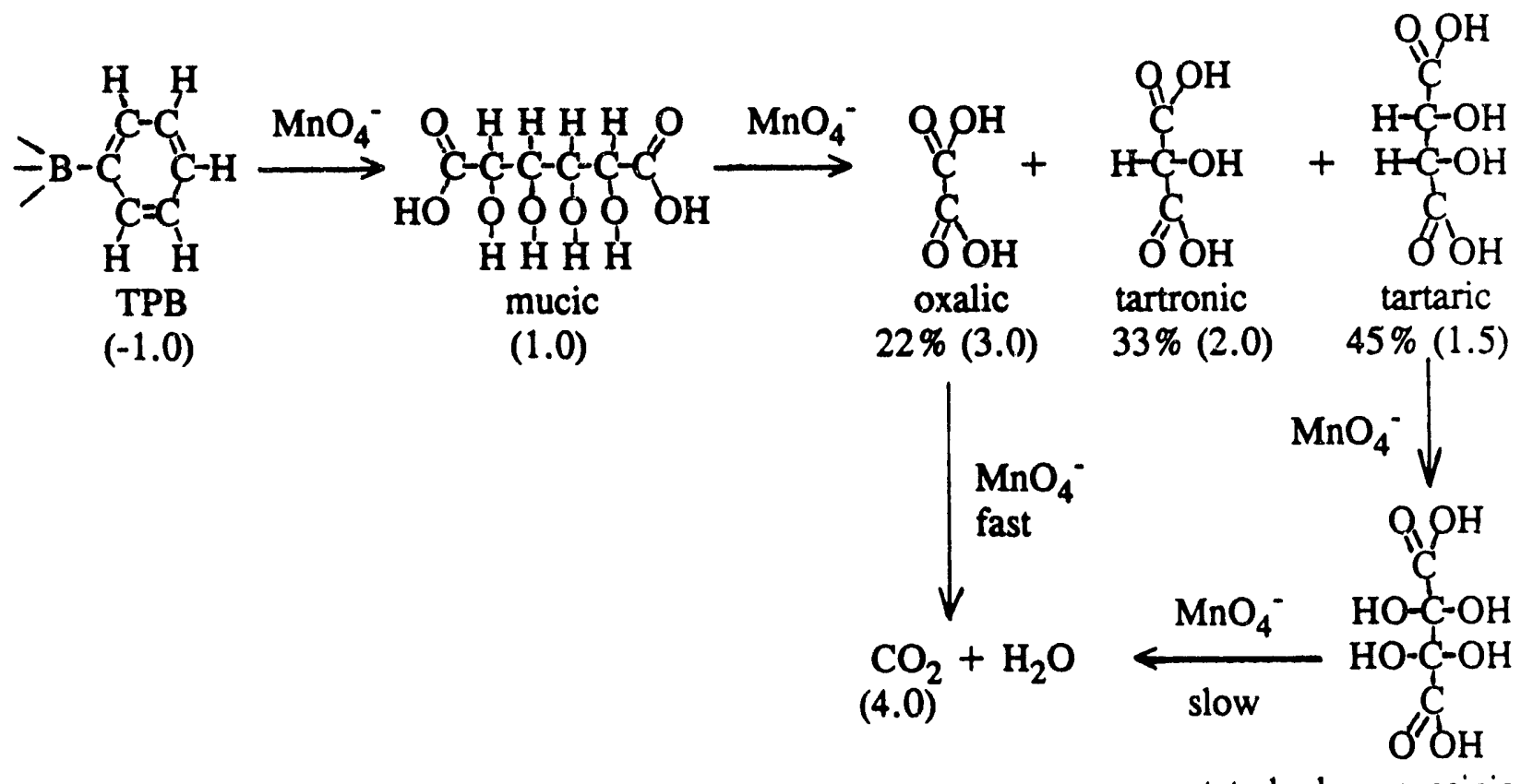

tetrahydroxysuccinic

Attack on the three inner carbon-carbon bonds of mucic acid should be quick relative to the end bonds due to steric hindrance of the later. Assuming these three bonds are attacked in equal proportion, with subsequent oxidation of the resulting primary carbon atoms; then oxalic, tartronic, and tartaric acids should be produced in near equal molar amounts. The oxalic, tartronic, and tartaric acids represent 22,33 , and $44 \%$ of the carbon in solution respectively. The numbers above in parenthesis are the average charge per carbon atom for each compound. 
WSRC-TR-93-139

$\mathrm{Pg} 7$ of 13

The oxalic acid is rapidly oxidized to $\mathrm{CO}_{2}$ and water. The tartronic acid should be relatively stable to further attack due to steric hindrance (mainly due to repulsion of the carbonyls with the oxygens of the permanganate). The middle carbon atoms of tartaric acid are a little less hindered and can be further oxidized to tetrahydroxysuccinic acid. Final oxidation to oxalic acid should be relatively slow (which then rapidly produces $\mathrm{CO}_{2}$ and water). The above outline fits the theory $2,3,4$ and the data (Table 1) which shows that $22 \pm 2 \%$ of the organic carbon is oxidized to $\mathrm{CO}_{2}$ in the first few hours, probably in the first few minutes. Letting the solution set overnight or increasing the temperature produces more $\mathrm{CO}_{2}$. Heating the solution to $95^{\circ} \mathrm{C}$ for three hours converted $70.5 \pm 2 \%$ of the carbon to $\mathrm{CO}_{2}$. This probably represented most of the tartaric acid and a small portion of the tartronic acid.

Decomposition of Acidic Permanganate Solutions

The decomposition of permanganate in dilute acid solution proceeds slowly at room temperature.

$$
4 \mathrm{MnO}_{4}^{-}+12 \mathrm{H}^{+} \longrightarrow 4 \mathrm{Mn}^{2+}+5 \mathrm{O}_{2}+6 \mathrm{H}_{2} \mathrm{O}
$$

The decomposition rate was measured as $0.37 \% /$ day in approximately $1 \mathrm{M}$ permanganate and $2.0 \mathrm{M}$ phosphoric acid at room temperature. This rate drops quickly with decreasing acid and permanganate concentration. Decomposition of a $0.6 \mathrm{M} \mathrm{NaMnO}_{4} / 2.5 \mathrm{M} \mathrm{H}_{3} \mathrm{PO}_{4}$ solution should be about four times slower.

\section{Oxalic Acid Reduction of Permanganate}

Reduction of permanganate with oxalic acid proceeds through a radical mechanism. The reaction is catalyzed by $\mathrm{Mn}^{2+}$ and therefore requires an induction period with fresh solution.

$$
2 \mathrm{MnO}_{4}^{-}+16 \mathrm{H}^{+}+5 \mathrm{C}_{2} \mathrm{O}_{4}{ }^{2-} \longrightarrow 2 \mathrm{Mn}^{2+}+10 \mathrm{CO}_{2}+8 \mathrm{H}_{2} \mathrm{O}
$$

If a significant amount of $\mathrm{Mn}^{2+}$ is already in solution, due to subsequent oxidation of KTPB, then the reaction should proceed quickly from the beginning at room temperature.

\section{DISCUSSION}

\section{Residual Organic Compounds}

A significant fraction of the organic carbon is left in solution, $>70 \%$, when KTPB is oxidized in acidic permanganate at room temperature. The product solution should contain oxidized compounds similar to tartronic and tartaric acids. A calculation of the average charge per carbon atom remaining in solution can be used to verify this last statement and this can be done if the beginning and end permanganate concentrations are known accurately. Subtracting off 5,3 , and 0 electrons respectively for every $\mathrm{CO}_{2}, \mathrm{CO}$, and benzene molecule produced in the oxidation and using the data from Table 1 , a value of 2.24 is obtained. This value implies compounds similar to tartronic and tetrahydroxysuccinic acid which have average charges of 2.0 and 2.5. These two compounds were expected from the theory ${ }^{2,3,4}$ and should be stable and are 
WSRC-TR-93-139

$\mathrm{Pg} 8$ of 13

very water soluble 5 .

\section{Benzene Vapor Loss}

The loss of TPB as benzene vapor is small, $0.16 \%$, which was expected for room temperature oxidation. Initial oxidation of the phenyl groups (benzene) of KTPB produces alcohol groups on the carbon ring (described earlier). These alcohol groups make the organic molecule less volatile and more water soluble. Only the KTPB that is able to hydrolyze (due to localized heating of the solution produced by the oxidation) will be able to escape.

$$
\mathrm{KB}\left(\mathrm{C}_{6} \mathrm{H}_{5}\right)_{4}+\mathrm{H}_{2} \mathrm{O} \longrightarrow \mathrm{KB}\left(\mathrm{C}_{6} \mathrm{H}_{5}\right)_{3} \mathrm{OH}+\mathrm{C}_{6} \mathrm{H}_{6} \text { (benzene) }
$$

Most of the heat of reaction, which is significant $(3,865 \mathrm{kcal} / \mathrm{mole} \text { TPB })^{6}$, is lost to the surrounding solution.

\section{Residual Benzene in Solution}

The residual benzene in solution was below the RCRA limit of $.5 \mathrm{ppm}$ for room temperature oxidation, .190 and $.071 \mathrm{ppm}$ (Table 1). Other benzene related compounds, such as phenol, should also have been destroyed since permanganate has a strong affinity for carboncarbon double bonds ${ }^{2,3,4}$. Benzene, TPB, and related aromatic compounds should not survive in acidic permanganate solutions above RCRA limits.

\section{Treatment of Solid KTPB}

The oxidation rate of KTPB is second order in permanganate concentration and first order in acid ${ }^{2,3,4}$. The oxidation rate with permanganate concentrations above $1 \mathrm{M}$, with at least a three fold excess of acid, is quite rapid. The rate for a $0.6 \mathrm{M} \mathrm{NaMnO} / 2.5 \mathrm{M} \mathrm{H}_{3} \mathrm{PO}_{4}$ is at least 4.5 times slower and is relatively well behaved. The oxidation rate should be sufficiently fast and complete down to at least .15M permanganate for further processing in about ten minutes. One liter of $0.6 \mathrm{M} \mathrm{NaMnO} / 2.5 \mathrm{H}_{3} \mathrm{PO}_{4}$ will destroy up to 8 grams of solid KTPB. This is the amount of KTPB expected to be in one sample sent from ITP for analysis. The residual permanganate should be about .15M and can be destroyed with about $600 \mathrm{ml}$ of $0.8 \mathrm{M}$ oxalic acid solution. The $\mathrm{pH}$ of the solution after destruction of the excess permanganate should be between 2 and $3^{7}$.

\section{Treatment of Dissolved TPB and Benzene}

Oxidation of benzene and related compounds dissolved in solution should react similarly to solid KTPB. Expected differences are a reduced benzene vapor loss during oxidation and slightly more foaming of the solution due to evolved product gases. Oxidation of solid KTPB occurs at the surface of the solution, KTPB floats, resulting in easier escape of the product gases.

When treating solutions containing dissolved TPB or benzene it is important to neutralize the solution and remove all compounds that will destroy the acid or permanganate. Compounds which will possibly be present and cause problems are base, nitrite, carbonate, and oxalate ${ }^{8}$. Acidifying the solution to a $\mathrm{pH}$ of 3 and letting the solution set stirring should remove the carbonate, nitrite (as nitrous acid), and oxalate (which will be destroyed by the generated nitrous 
acid). The waste solution can then be added directly to the permanganate solution. If a gram per liter of TPB or less is dissolved in the waste solution, approximately three liters of waste solution can be added per liter of permanganate solution. This equates to about a $33 \%$ increase in waste volume.

\section{Safety of Permanganate Oxidation Process}

Permanganate solids and concentrated solutions are strong oxidizers, especially in acidic solution. The permanganate oxidation of TPB compounds can be performed safely as long as the appropriate safety precautions are taken and low permanganate and acid concentrations are

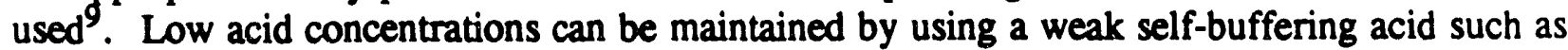
$\mathrm{H}_{3} \mathrm{PO}_{4}$ or $\mathrm{NaHSO}_{4}$. The heat produced in the oxidation of $8 \mathrm{grams}$ of KTPB should be about $52 \mathrm{kcal}^{6}$, which is less than the maximum $86 \mathrm{kcal}$ due to incomplete oxidation. Much of the heat produced is lost to the product gases, $\mathrm{CO}_{2}$ and $\mathrm{H}_{2} \mathrm{O}$. The solution temperature has been found experimentally to increase to only about $40^{\circ} \mathrm{C}$, far from the maximum $110^{\circ} \mathrm{C}$. A total of 3.5 liters of gas should be released from the oxidation of 8 grams of KTPB. This release occurs over about two minutes in a controlled fashion. If a higher concentration for either permanganate or acid is desired then tests should be performed to determine the rate, mildness (or violence), of the reaction at the new reaction conditions. A safety analysis has been performed for this oxidation process?.

\section{ACKNOWLEDGEMENTS}

This work has benefitted from the constructive comments and analytical support of J. E. Young of ADS/SRTC. 
WSRC-TR-93-139

Pg 10 of 13

TABLE 1

KTPB Oxidation by Permanganate in Dilute Phosphoric Acid (1.5-2.0M)

\begin{tabular}{|c|c|c|c|c|c|c|c|}
\hline $\begin{array}{l}\text { Organic } \\
\text { (grams) }\end{array}$ & $\begin{array}{l}{\left[\mathrm{MnO}_{4}^{-}\right]} \\
\mathrm{initial} / \text { final }\end{array}$ & $\mathrm{T}\left({ }^{\circ} \mathrm{C}\right)$ & $\% \mathrm{CO}_{2}$ & $\% \mathrm{CO}$ & $\begin{array}{c}\mathrm{C}_{6} \mathrm{H}_{6} \text { sol. } \\
(\mathrm{ppm})\end{array}$ & $\begin{array}{l}\% \mathrm{C}_{6} \mathrm{H}_{6} \\
\text { vapor }\end{array}$ & $\begin{array}{l}\text { \%C sol. } \\
\text { (TOC) }\end{array}$ \\
\hline \multirow[t]{2}{*}{$\begin{array}{l}\text { KTPB } \\
(1.178 \\
\pm .004) \\
\end{array}$} & $\begin{array}{c}\sim 1.0 \\
\text { (initial) } \\
500 \mathrm{ml}\end{array}$ & 23 & - & - & 190 & - & - \\
\hline & $\begin{array}{c}.43 \pm .01 \\
\text { (final) }\end{array}$ & 70 & $60 \pm 5$ & - & .180 & - & - \\
\hline \multirow[t]{4}{*}{$\begin{array}{l}\text { KTPB } \\
(.148 \\
\pm .002) \\
\end{array}$} & $\begin{array}{l}.200 \pm .001 \\
\text { (initial) } \\
250 \mathrm{ml} \\
\end{array}$ & 23 & $22.2 \pm 2$ & - & - & - & - \\
\hline & - & 23 & $\begin{array}{l}33.4 \pm 2 \\
(20 \mathrm{hrs})\end{array}$ & - & - & - & - \\
\hline & $\begin{array}{c}.158 \pm .002 \\
\text { (final) }\end{array}$ & 47 & $50.6 \pm 2$ & $1.8 \pm 2$ & .071 & 0.16 & $\begin{array}{c}38.4 \\
(55 \mathrm{ppm})\end{array}$ \\
\hline & & 95 & $70.5 \pm 2$ & $6.3 \pm 2$ & - & - & - \\
\hline
\end{tabular}


WSRC-TR-93-139

Pg 11 of 13

\section{FIGURE 1}
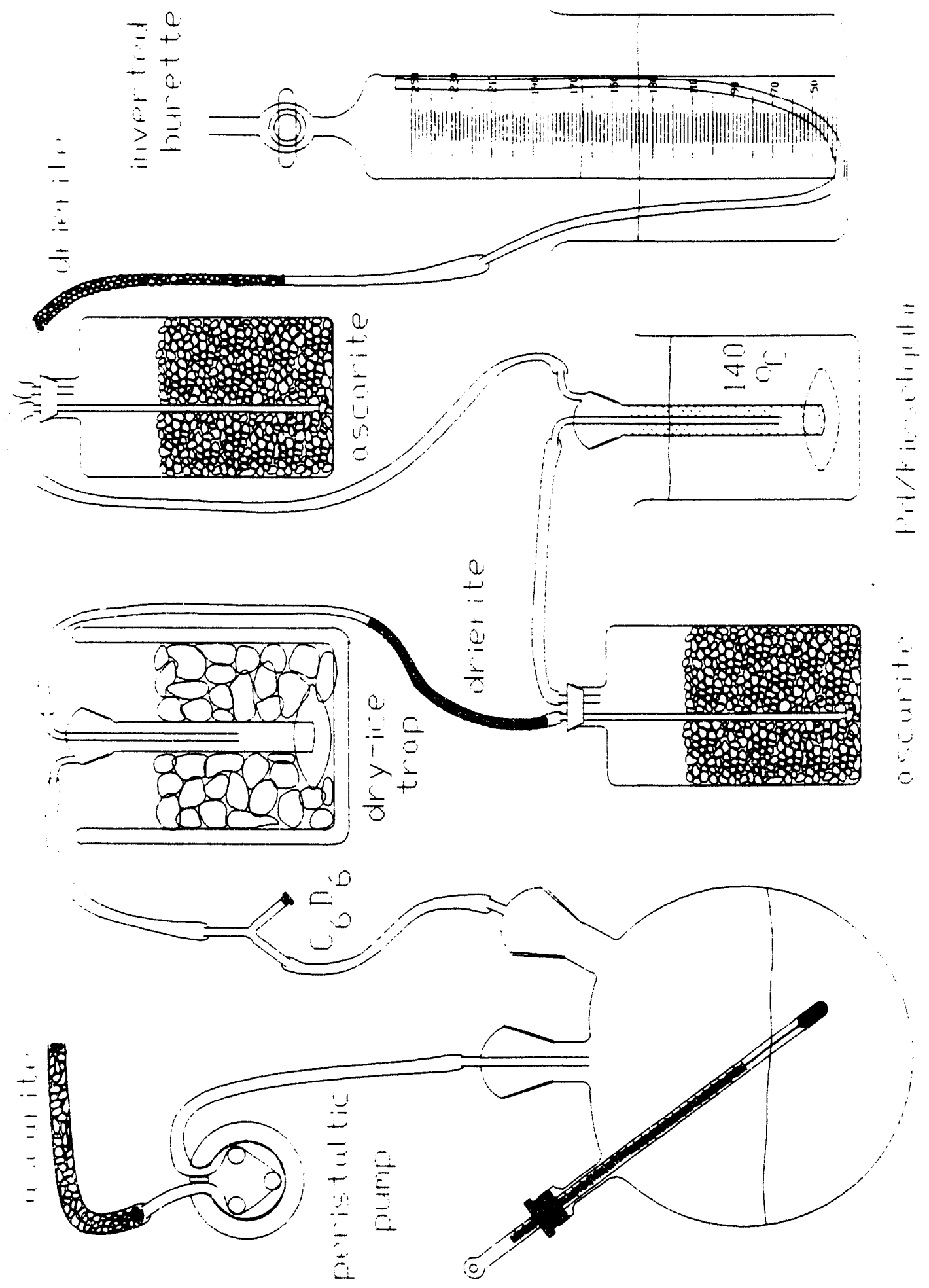
WSRC-TR-93-139

$\mathrm{Pg} 12$ of 13

\section{REFERENCES}

1. $\quad$ R.S. McBride, J. Am. Chem. Soc., 34, 393 (1912).

2. J.W. Ladbury and C.F. Cullis, Kinetics and Mechanism of Oxidation by Permanganate, Chem. Rev., 58, No.2, $402-438$ (1958).

3. A.L. Ternay, Jr., Contemporary Organic Chemistry, $2^{\text {nd }}$ ed., W.B. Saunders Co., Philadelphia, 329-333 (1979).

4. J. March, Advanced Organic Chemistry, Reactions, Mechanisms, and Structure, $2^{\text {nd }}$ ed., McGraw-Hill Book Co. (1977).

5. R.C. Weast and S.M. Selby, Handbook of Chemistry and Physics, $47^{\text {th }}$ ed., The Chemical Rubber Co., Cleveland, Ohio (1966).

6. R.E. Dickerson, Molecular Thermodynamics, W.A. Benjamin, Inc., Menlo Park, CA (1969).

7. Micromath Scientific Software, Equil - Solution Chemical Equilibrium Calculations, Micromath Inc., Salt Lake City, Utah (1990).

8. D.D. Walker and B.A. Hamm, Material Balance and Planned Operating Schedule for the In-Tank Process (U), WSRC-RP-89-1303, Savannah River Site, Aiken, SC 29808 (1989).

9. J.R. Smith, Permanganate Oxidation of TPB/Benzene (Safety Analysis), SRL Internal Report SRL-CTS-92-240, Savannah River Site, Aiken, SC 29808 (1992). 
Distribution:
A.L. Blancett, 773-A
F.R. Graham, 773-A
C.E. Coffey, 773-A
W.L. Tamosaitis, 773-A
S.T. Goforth, 773-A
W.R. Wilmarth, 773-43A
R.A. Runnels, 773-43A
P.F. Cloessner, 773-A
W.E. Stevens, 773-A
M.C. Thompson, 773-A
K. Andringa, 773-41A
C.J. Coleman, 773-A
J.E. Young, 773-A
B.K. Culligan, 773-43A
J. Park, 241-152H
SRTC Records(4)
CTS/STRC Records 

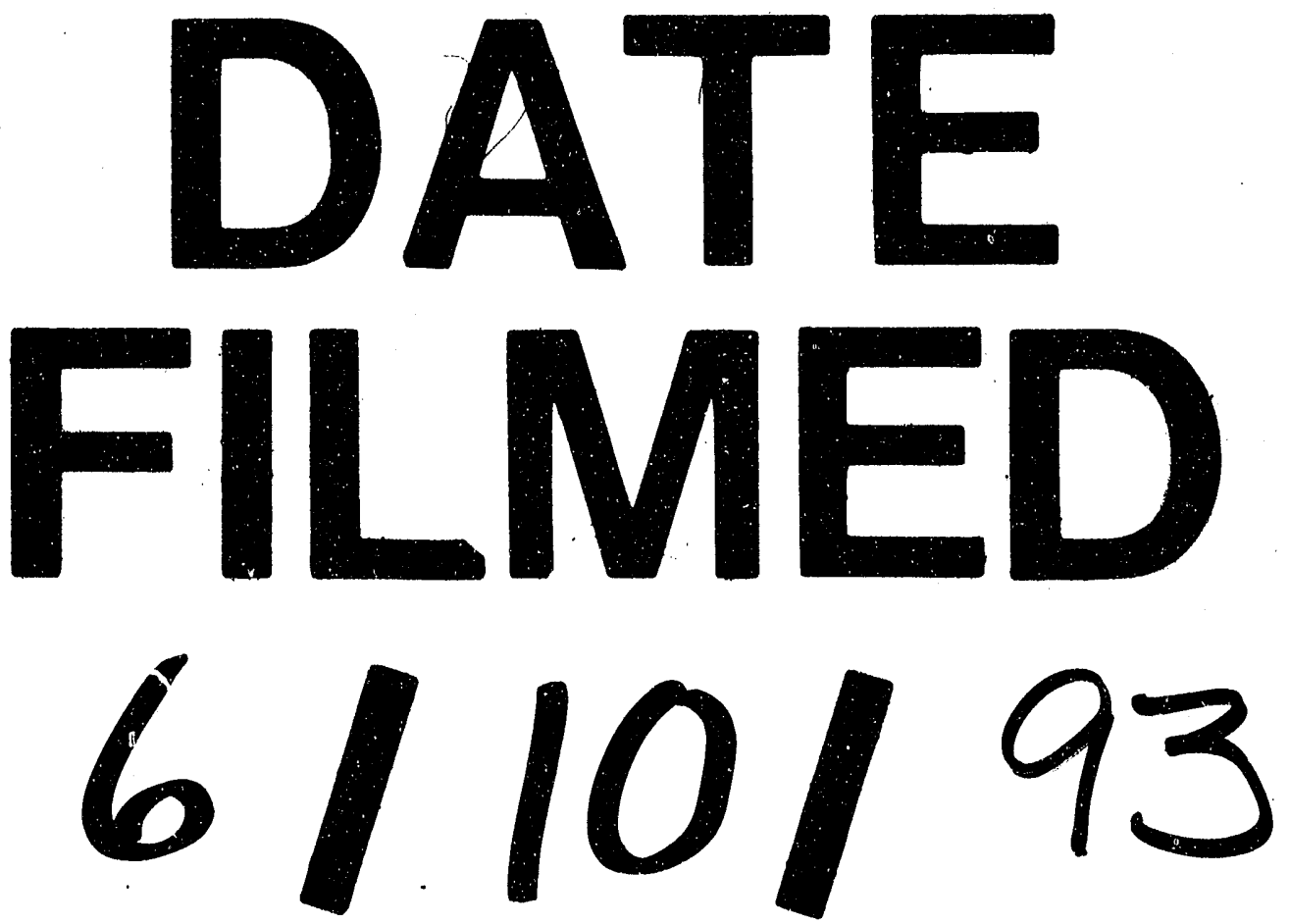
